\title{
Commercial Transition to LEDs: A Pathway to High-value Products
}

\author{
Gary W. Stutte ${ }^{1}$ \\ Sustainable Systems Group, Mail Code ESC-24, Headquarters Building, Kennedy Space Center, FL 32899 \\ Additional index words. controlled environment agriculture, vertical farming, NASA, greenhouse lighting, medicinal plants, Internet
}

\begin{abstract}
The use of light-emitting diodes (LEDs) to support plant growth is a radical departure from use of gas-discharge lamps, which were developed in mid-19th and widely adopted by the industry during the 20th century. Initial investigation by the National Aeronautics and Space Administration (NASA) in the late 1980s on the use of LEDs to grow plant in space is resulting in an industry-wide transition from gas discharge to solid-state lighting systems. This global transformation is given urgency by national policies to reduce energy consumption and being facilitated by ready access to information on LEDs. The combination of research, government policy, and information technology has resulted in an exponential increase in research into the use and application of LED technology in horticulture. Commercial horticulture has identified the opportunities provided by LEDs to optimize light spectra to promote growth, regulate morphology, increase nutrient content, and reduce operating costs. LED-light technology is enabling the development of innovative lighting systems, and is being incorporated into large-scale plant factories for the production of edible, ornamental, and medicinal plants. An overview of prevalence of readily accessible information on LEDs and implications for future adoption in horticulture is discussed.
\end{abstract}

LED technology is fundamentally altering the use and application of supplemental lighting for controlled environment agriculture. This paper provides a brief overview of the rapid development of LED lighting and some thoughts on the future application in horticulture.

Carl Wilhelm Siemens tested electric carbon-arc lamps on plant growth in the mid-to-late 1880s and coined the term "electro horticulture" to define this application of electric lamps. He postulated that "the horticulturist will have the means of making himself practically independent of solar light for producing a high quality of fruit at all seasons of the year" (Siemens, 1881). Liberty Hyde Bailey, reporting experiments performed at Cornell University with electric carbon-arc lamps wrote "There is every reason, therefore, to suppose that the electric light can be profitably used in the growing of plants" and concludes with "On the whole, I am inclined towards Seimens view that there is a future for electro-horticulture" (Bailey, 1891). Both these predictions have been realized, with supplemental lighting being routinely used in commercial greenhouse production to promote growth and extend

Received for publication 1 Apr. 2015. Accepted for publication 3 June 2015.

This paper was presented as part of the workshop "Advances in Commercial-ready LED Technologies for Horticulture" during the ASHS Annual conference, 28-31 July 2014, Orlando, FL.

Author acknowledges the support of NASA's Engineering Service Contract at the John F. Kennedy Space Center, Florida, and the Office of Research, Development and Enterprise, Limerick Institute of Technology, Moylish Park, Limerick, Ireland, of this work.

Mention of a trademark, proprietary product, or vendor does not constitute a guarantee or warranty of the product and does not imply its approval to the exclusion of other products or vendors that also may be suitable.

${ }^{1}$ Corresponding author. E-mail: gary.w.stutte@ nasa.gov. daylength. The advancements in horticulture lighting have closely followed refinements of this 19th century technology for modern residential and commercial lighting applications (Wheeler, 2008).

NASA's funding of research on use of LEDs as a light source for space-based plant growth systems in the late 1980s signaled the beginning of the transformation of horticultural lighting from high-intensity discharge lamps to LEDs (Barta et al., 1992; Wheeler, 2008). Scientists at the University of Wisconsin tested low-output red $(\approx 660 \mathrm{~nm})$ LEDs as lighting sources and demonstrated the feasibility of this fundamentally new approach to providing lighting for plants (Barta et al., 1990; Bula et al., 1991; Hoeghn and Luttges, 1990; Hoenecke et al., 1989). This led to the patenting of LED technology for plant growth in the United States (Ignatius et al., 1991) and LEDs were soon incorporated into instrumentation to study photobiology, photosynthesis, and plant physiology (Tennessen et al., 1994). NASA has continued to fund this research over the ensuing decades and the effects of LEDs on growth and productivity of a number of plant species has been reported (Goins et al., 1997; Kim et al., 2005; Massa et al., 2008; Mitchell, 2012; Morrow, 2008; Stutte et al., 2009).

The technical advances in LED technology have increased output, electrical efficiency, and availability of wavelengths suitable for horticultural use (Stutte, 2009), enabling increases in research and commercial development, with several companies developing multiwavelength LED fixtures for the horticulture industry. The technical advancement in LED lighting is driven by consumer and regulatory demand to replace inefficient light sources in residential, commercial, and industrial applications (Morrow, 2008). Advancements have been so rapid and predictable that the Haitz model (Haitz and Tsao, 2011), which states that the amount of light generated per LED is increasing 20fold, and cost decreasing 10-fold, has been advanced to describe it.
So how does this relate to horticultural research? First, there has been an explosion of research reports on application of LEDs in ornamental, vegetable, and nursery crops that has followed the increased output, decreased costs, and widespread availability of LEDlighting systems. Figure 1 illustrates the exponential increase in research for the 25 -year period from 1990 to 2015 . A general online search using criteria "Light emitting diodes" and "Horticulture" digital search engine limited to academic sources (scholar.google.com, accessed 14 July 2014) returned 102 items (journals articles, patents, and journal citations) in the 5 years (1990-95) following the first reports of successful growth of plants under red LEDs. A decade later (2001-05), the same search criteria returned 1130 results, a 10-fold increase, and it's on track to approach 10,000 articles, or over 2000/year, for the period from 2011 to 2015 !

The use of this search engine-based approach to assess research productivity is limited in that it may include duplication, is biased toward English language journals, and only searches articles indexed in Google Scholar (gudes.lib.umich.edu, accessed 12 Dec. 2014). While acknowledging the shortcomings of this approach with regards to providing a precise number of original research articles being published, Fig. 1 clearly illustrates that an exponential increase in information on LEDs to support horticulture is occurring.

While to my knowledge, no systematic studies have been performed to assess the role of Internet in the adoption of LED technology by the industry, is clear that widespread access to the Internet, and effective tools to search and retrieve decentralized, remotely stored digital information (e.g., Mosaic, WebCrawler, Yahoo!, Google, and Bing) has been concurrent with the development of LED technology. These digital information tools provide commercial growers, along with the general public, easy access to cutting edge research that is unparalleled in history. 


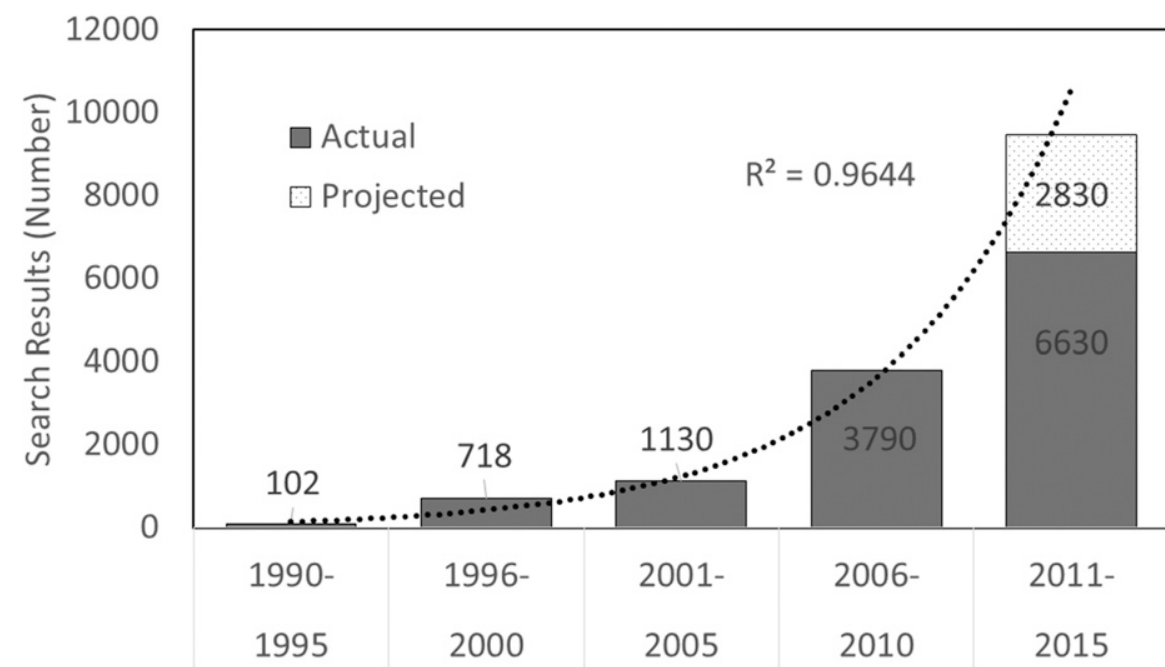

Fig. 1. Results from Internet search of scholarly articles (scholar.google.com), using key words "Horticulture" and "Light Emitting Diodes." The search results include peer reviewed papers, theses, books, abstracts, and technical reports from a broad range of disciplines. The number of citations from 2015 was projected based on previous year's rate of increase. No categorization of results has been performed.
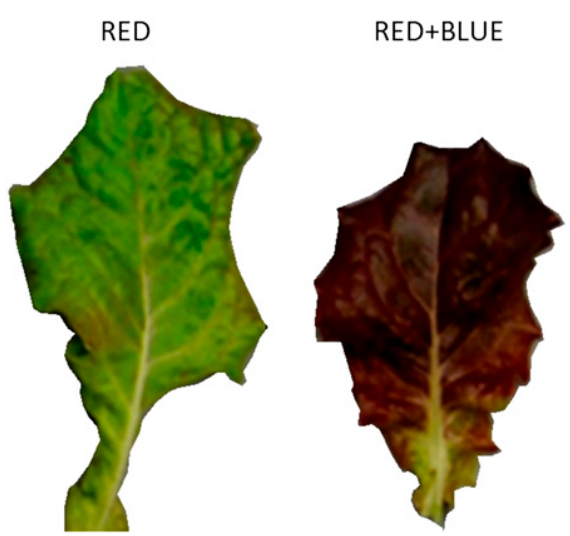

Fig. 2. Addition of blue light prior to harvest results in higher concentration of anthocyanin in Lactuca sativa cv. Outredegous. Leaves were harvested $28 \mathrm{~d}$ after planting. Plants were grown at $280 \mu \mathrm{mol} \cdot \mathrm{m}^{-2} \cdot \mathrm{s}^{-1}$ photosynthetically active radiation $(P A R)$ under monochromatic $640 \mathrm{~nm}$ red light-emitting diode (red) or under red light with an additional of $20 \mu \mathrm{mol} \cdot \mathrm{m}^{-2} \cdot \mathrm{s}^{-1} P A R$ $440 \mathrm{~nm}$ blue from day 21 to 28 (Red and Blue). (Adapted from Stutte et al., 2009.)

Widespread access to technical information, coupled with digital tools for distributing new or repackaged data via e-mail, user groups, video, and social media has arguably accelerated the pace of adoption of LED technology by horticulturists.

The capacity for digital distribution of research results, and availability of the Internet to access this data, has resulted in the proliferation of research reports, field observations, and user experiences with LEDs being distributed to scientists, hobbyists, commercial growers, lighting manufacturers, and distributors. The amount of information available is staggering. A search (www.google. com, accessed 14 Dec. 2014) of "LED Lighting" resulting in an estimated 32,500,000 web pages! The following data provide a snapshot of this digital landscape, and are indicators of the power of digital media to disseminate information relevant to the commercial use of LEDs in horticulture. lighting for commercial horticulture was illustrated by conducting a targeted Internet search of specific plant species. This was done by delimiting the search (www.google. com, accessed 14 July 2014) to "Light Emitting Diodes" and " crop scientific name \}" for five of species, Solanum lycopersicum L. (tomato), Lactuca sativa L. (lettuce), Petunia $\times$ hybrida (Petunia), Triticum aestivum L. (wheat), and Cannabis sativa L. (marijuana) representing vegetable, ornamental, agronomic, and medicinal crops. This resulted in an estimated 124,000 web pages devoted to LEDs and tomato, 156,000 pages for lettuce, 180,000 for wheat, 690,000 pages for petunia, and in excess of 2 million for marijuana!

The sheer volume of freely available information indicates that research on LEDs and plant growth, both professional and amateur, is being widely distributed and presumably informing decision makers on the selection This democratization of research and ease of access to information is exciting in that it provides the opportunity to accelerate the development and commercial adoption of LED lighting and to identify new and unique means of applying this technology. This explosion in information also presents a unique challenge to end users to accept the risk that misinformation is being perpetuated and acknowledge their responsibility to critically review information retrieved from online sources.

It is not possible to establish exactly how much of the digital information is derived from, or distributed by, nontraditional research groups, but it is clear that a significant portion of it has not been subject to the scientific rigor typically associated with aca-
The proliferation of information on LEDand use of LEDs in horticultural production. demic and government research centers. For example, a search for instructional videos (www.youtube.com, accessed 14 Jan. 2014) using search criteria "LED" and "Cannabis" identified 51,100 videos available for viewing. A screening of the top 50 videos provided a cross section of grower results comparing the horticultural response of dozens of $C$. sativa strains under different light sources, LED spectra, and controlledenvironment conditions: none of which underwent external review. Despite the lack of independent evaluation, one online review of LED technology, which provided recommendations based on unreplicated, anecdotal information, had been viewed over 500,000 times in less than a year $(\approx 1400$ time/day!).

Despite these shortcomings in digital distribution of objective information on LEDs, the early experiences with commercial adoption of solid-state lighting in horticulture have been encouraging, with the initial finding being a reduction of operating cost due to the higher electrical efficiency of fixtures (Morrow, 2008). The reduced operating cost has been a primary driver for adoption in residential, commercial, and horticultural applications. The increased efficiency of LEDs for residential lighting are resulting in government policy decisions being made in North America and Europe to accelerate the transition to LEDs from incandescent and fluorescent lamps to reduce energy demand. A global effort to offset rising $\mathrm{CO}_{2}$ concentrations by increasing efficiency of lighting spectra, and reducing overall energy requirements is resulting in tax incentives for adoption and regulatory penalties for noncompliance to phaseout traditional supplemental light sources (Yamada and Chwastyk, 2013). The inclusion of LED technology in government policy is resulting in regulatory and labeling guidelines that manufacturers must meet. A search of the EUR0-Lex database (eur-lex.europa.eu, accessed 14 May 2014), which provides access to European Union (EU) Law (EU treaties, directives, regulations, decisions, consolidated legislation, etc.) for member states of the $\mathrm{EU}$ identified 130 regulatory compliance guidance documents issued by the European Commission related to LEDs in general. Of those, 86 have sections related to horticultural lighting and 30 include specific guidance for greenhouse operations.

The regulatory requirement for conversion to high-efficiency LEDs as a replacement light source in residential and business settings is driving the development of less expensive, energy efficient LED fixtures by manufacturers. This advancement is being encouraged by governments in two ways. The first is the banning of inefficient technologies (e.g., incandescent lamps) and the second is passing stringent legislation for energy efficiency and providing tax incentives to adopt LED lighting. It has been estimated that LEDs occupied $7 \%$ of the global replacement lighting market in 2008 and $20 \%$ in 2010 , with projections of significant share of global horticultural 


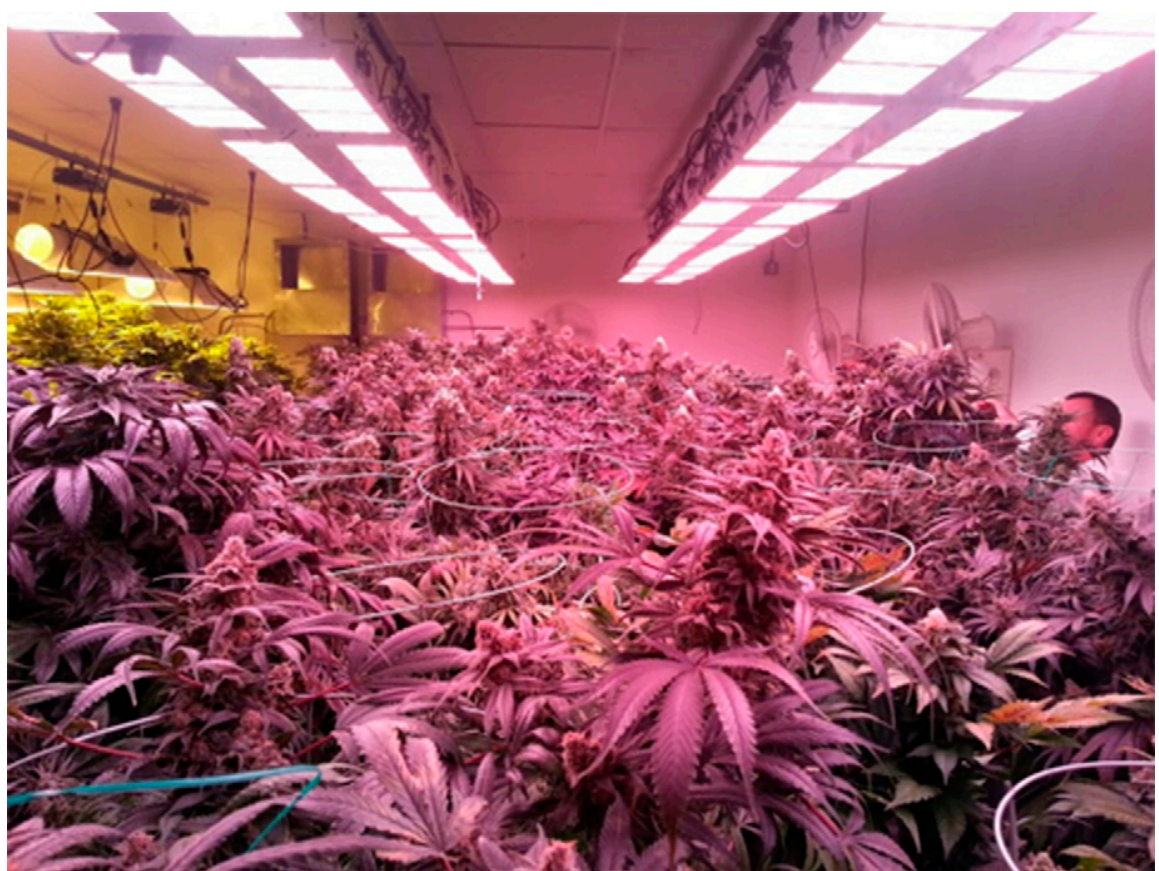

Fig. 3. Production of medicinal plants (Cannabis sativa) under controlled-environment rooms using lightemitting diodes as primary light source. (Photo courtesy of Ryan Ryall and Neil Yorio, Bios LLC.)

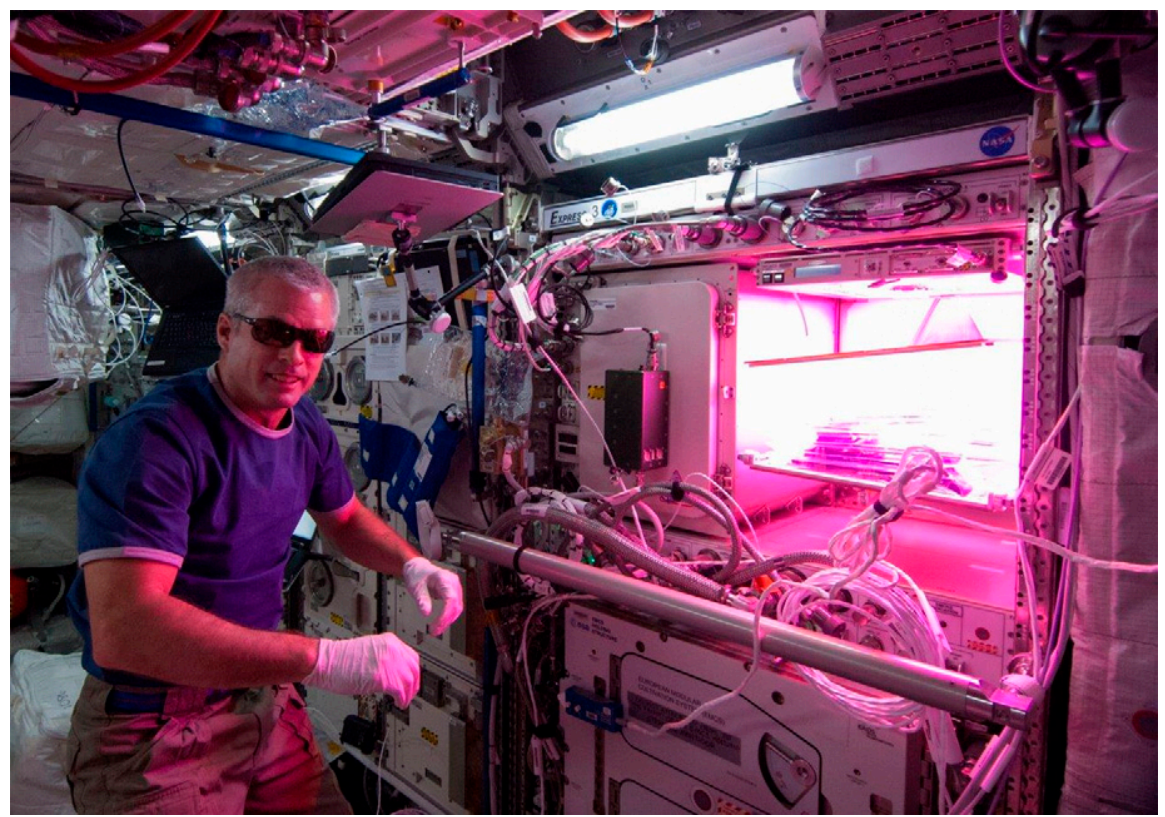

Fig. 4. International space station (ISS) crew member, Dr. Steve Swanson tending the vegetable production system (veggie) on ISS during expedition 40. Veggie is a plant growth system installed on ISS which uses a light-emitting diode lighting system that is designed to produce salad-type crops to provide the crew with fresh food while on orbit. (Photo courtesy of NASA Public Affairs Office.)

replacement lighting market by 2020 (McKinsey and Co, 2012). These actions to regulate the primary lighting market segments (general residential and commercial lighting, automotive lighting, and backlighting) are necessitating the transition of commercial horticulture away from gas-discharge lamps to LEDs. This transition presents tremendous challenges and opportunities for the commercial grower.

The most immediate challenge is understanding that each LED fixture has a unique content of horticultural crops through photoinduction of bioactive phytochemicals during the growth cycle (Fig. 2) (Stutte et al., 2009). The ability to increase the concentration of these bioactive compounds has been shown in a wide diversity of horticultural species including lettuce (Li and Kubota, 2009; Son and Oh, 2013; Stutte et al., 2009), kale (Brassica oleracea) (Lesfsrud et al., 2008), broccoli (B. oleracea italica) (Kopsell and Sams, 2013), strawberry (Fragaria $\times$ ananassa) (Choi et al., 2013), and tomato (Solanum lycoperiscum) (Kalwalcyzk et al., 2012). LEDs are also finding wide utility in the production of ornamental species during tissue culture (Gupta and Jatathu, 2013), vegetative (Currey and Lopez, 2013) and seed (Randall and Lopez, 2014) propagation of a growing number of species. LEDs are being used to manage the morphology of seedlings (Wollaeger and Runkle, 2013), transplants (Kozai, 2007), and grafted seedlings (Chia and Kubota, 2010).

The solid-state characteristics of LEDs, the lack of heat at the LED surface, and high light output is enabling the development of innovative lighting systems such as intracanopy lighting (Massa et al., 2005), programmable lighting (Poulet et al., 2014), multilevel indoor plant factories (Kozai, 2013), and space-based plant growth systems (Stutte et al., 2015). There is widespread adoption of LEDs in production of high-value medicinal crops across North America and Europe (Badertscher and Badertscher, 2014).

\section{CONCLUSION}

The use of LEDs to support plant growth is a radical departure from traditional gas-discharge lamps developed in the mid-19th century and refined throughout the 20th century (Downs, 1994). The initial investments by NASA in solid-state lighting research is enabling improved energy efficiency, reduced operating and management costs, and enhanced quality for traditional commercial crops (Fig. 2); is being widely adopted by emerging high-value medicinal plant production (Fig. 3), and supporting the production of food in space (Fig. 4). The adoption of this technology holds great promise for the future of commercial horticulture to manage photobiology and plant physiology for the production of highquality, high-value products.

\section{Literature Cited}

Badertscher, K.B. and K. Badertscher. 2014. Cannabis for capitalists: Commercial horticulture tools, techniques, materials and resources. Otoké Horticulture.

Bailey, L.H. 1891. Some preliminary studies of the influence of the electric arc light upon greenhouse plants. Cornell Univ. Agr. Expt. Bul. 30.

Barta, D.J., R.J. Bula, and T.W. Tibbitts. 1990 Wheat growth under a light emitting diode irradiance sources. ASGSB Bul. 4(1):50.

Barta, D.J., T.W. Tibbitts, R.J. Bula, and R.C. Morrow. 1992. Evaluation of light emitting diode characteristics for a space-based irradiation source. Adv. Space Res. 12:141-149.

Bula, R.J., R.C. Morrow, T.W. Tibbitts, D.J Barta, R.W. Ignatius, and T.S. Martin. 1991. 
Light-emitting diodes as a radiation source for plants. HortScience 26:203-205.

Chia, P.-L. and C. Kubota. 2010. End-of-day farred light quality and dose requirements for tomato rootstock hypocotyl elongation. HortScience 45:1501-1506.

Choi, H.G., J.K. Kwon, B.Y. Moon, N.J. Kang, K.S. Park, M.W. Cho, and T.C. Kim. 2013. Effect of different light emitting diode (LED) on the growth characteristics and phytochemical production of strawberry fruits during cultivation. Korean J. Hort. Sci. Tech. 31:56-64.

Currey, C.J. and R.G. Lopez. 2013. Cuttings of Impatiens, Pelargonium, and Petunia propagated under light emitting diodes and highpressure sodium lamps have comparable growth, morphology, gas exchange, and post-transplant performance. HortScience 48:428-434.

Downs, J. 1994. History and applications in controlled environments. Intern. Lighting in Controlled Environments Workshop. p. 69-87.

Folta, K.M. and K.S. Childers. 2008. Light as a growth regulator: Controlling plant biology with narrow-band solid-state lighting systems. HortScience 43:1957-1962.

Goins, G.D., N.C. Yorio, N.N. Sanwo, and C.S. Brown. 1997. Photomorphogenisis, photosynthesis and seed yield of wheat plants grown under red-light emitting diodes (LEDs) with and without supplemental blue lighting. J. Expt. Bot. 48:1407-1413.

Gupta, S.D. and B. Jatathu. 2013. Fundamentals and applications of light emitting diodes (LEDs) in in vitro plant growth and morphogenesis. Plant Biotechnol. Rpt. 7:211-220.

Haitz, R. and J.Y. Tsao. 2011. Solid-state lighting: The case 10 years after and future prospects. Phys. Status Solidi 208:17-29.

Hoeghn, A. and M.W. Luttges. 1990. Tuning the efficiencies of plant lighting systems: From primary energy to edible biomass-the LED as an alternative light source. Life Sciences Research in Space, Fourth European Symposium, Trieste, Italy. ESA-SP-307, European Space Agency.

Hoenecke, M.E., R.J. Bula, and T.W. Tibbitts. 1989. Lettuce seedling response to red light emitting diodes supplemented with varying levels of blue photons. ASGSB Bul. 3(1):59 (abstr.).
Ignatius, R.W., T.S. Martin, R.J. Bula, R.C. Morrow, and T.W. Tibbitts. 1991. Method and apparatus for irradiation of plants using optoelectronic devices. U.S. patent no. 5,012,609.

Kalwalcyzk, K., J. Gajc-Wolska, A. Metera, K. Mazu, J. Radzanowska, and M. Szatkowski. 2012. Effect of supplementary lighting on the quality of tomato fruit (Solanum lycoperiscum L. in autumn-winter cultivation. Acta Hort. 956:395-402.

Kim, H.H., R.M. Wheeler, J.C. Sager, N.C. Yorio, and G.D. Goins. 2005. Light-emitting diodes as an illumination source for plants: A review of research at Kennedy Space Center. Habitation (Elmsford) 10:71-78.

Kopsell, D.A. and C.E. Sams. 2013. Increase in shoot tissue pigments, glycosinolates and mineral elements in sprouting broccoli after exposure to short-duration blue light from light emitting diodes. HortScience 138:31-37.

Kozai, T. 2007. Propagation, grafting and transplant production in closed systems with artificial lighting for commercialization in Japan. Prop. Ornam. Plant. 7:145-149.

Kozai, T. 2013. Plant factory in Japan: Current situation and perspectives. Chron. Horticult. 53:8-11.

Lesfsrud, M., D. Kopsell, and C. Sams. 2008 Irradiance from distinct wavelength lightemitting diodes affect secondary metabolites in kale. HortScience 43:2243-2244.

Li, W. and C. Kubota. 2009. Effects of supplemental light quality on growth and phytochemicals of baby leaf lettuce. Environ. Expt. Bot. 67:59-64.

Massa, G.D., J.C. Emmerich, M.E. Mick, R.J Kennedy, R.C. Morrow, and C.A. Mitchell. 2005. Development and testing of an efficient LED intracanopy lighting design for minimizing equivalent system mass in an advanced lifesupport system. Gravit. Space Biol. Bul. 18:87-88.

Massa, G.D., H. Kim, R.M. Wheeler, and C.A. Mitchell. 2008. Plant productivity in response to LED lighting. HortScience 43:1951-1956.

McKinsey \& Co. 2012. Lighting the way: Perspectives on the global lighting market. 2nd ed.

Mitchell, C.A. 2012. Plant lighting in controlled environments for space and earth applications. Acta Hort. 956:23-26.
Morrow, R.C. 2008. LED lighting in horticulture. HortScience 43:1947-1950.

Poulet, L., G.D. Massa, R.C. Morrow, C.M. Bourget, R.M. Wheeler, and C.A. Mitchell. 2014. Significant reduction in energy for plant-growth lighting in space using targeted LED lighting and spectral manipulation. Life Sci. Space Res. 2:43-53.

Randall, W.C. and R.G. Lopez. 2014. Comparison of supplemental lighting from high-pressure sodium lamps and light emitting-diodes during bedding plant seedling production. HortScience 49:589-595.

Siemens, C.W. 1881. On some applications of electric energy to agricultural and horticultural purposes. Brit. Assoc. Adv. Sci. Rep. p. 474 480.

Son, K.H. and M.M. Oh. 2013. Leaf shape, growth, and antioxidant phenolic compounds of two lettuce cultivars grown under various combinations of blue and red light-emitting diodes. HortScience 48:988-995.

Stutte, G.W. 2009. Light-emitting diodes for manipulating the phytochrome apparatus. HortScience 44:231-234.

Stutte, G.W., S. Edney, and T. Skerritt. 2009. Photoregulation of bioprotectant content of red leaf lettuce with light-emitting diodes. HortScience 44:79-82.

Stutte, G.W., O. Monje, and R.M. Wheeler. 2015. The International Space Station (ISS) researchers guide to plant science. NASA NP-2015-03014-JSC.

Tennessen, D.J., E.L. Singsaas, and T.D. Sharkey. 1994. Light-emitting diodes as a light source for photosynthesis research. Photosyn. Res. 39:85-92.

Wheeler, R.M. 2008. A historical background of lighting: An introduction to the workshop. HortScience 43:1942-1943.

Wollaeger, H.M. and E.S. Runkle. 2013. Growth responses of ornamental annual seedlings under different wavelengths of red light provided by light-emitting diodes. HortScience 48:1478-1483.

Yamada, M. and D. Chwastyk. 2013. Adoption of light-emitting diodes in common lighting applications. U.S. Department of Energy. DOE/ EE-1016. 